\title{
COMO DESENVOLVER O COMPORTAMENTO EMPREENDEDOR? A EAD - UNIUBE FORMANDO MAIS QUE PROFISISONAIS
}

UBERABA/MG MAIO/2018

\author{
CAMILLA DE OLIVEIRA VIEIRA - UNIUBE - gestor.administracao@uniube.br \\ SILVIA DENISE DOS SANTOS BISINOTTO - UNIUBE - silvia.bizinoto@uniube.br \\ THAÍS BORGES DUARTE - UNIUBE - thaisbduarte@hotmail.com
}

\author{
Tipo: Relato de Experiência Inovadora (EI) \\ Categoria: Conteúdos e Habilidades \\ Setor Educacional: EDUCAÇÃO SUPERIOR
}

\begin{abstract}
RESUMO
As universidades, produtoras e difusoras de conhecimento, constituem-se em importantes espaços para práticas de desenvolvimento empreendedor. Frente a este cenário, os cursos da Universidade de Uberaba se preocupam em formar profissionais preparados para lidar com situações que exigem aprendizado contínuo, criatividade, inovação e empreendedorismo em todas as áreas e dimensões da vida humana, individual e coletiva. O processo de empreendedorismo, inovação e transferência de conhecimento é dinâmico, complexo e interativo, pois deve existir um fluxo de informações entre os agentes envolvidos no processo de produção do conhecimento. Este é caracterizado como uma contínua atividade de pesquisa, composta e estruturada pelas forças econômicas, pelo conhecimento tecnológico e pela demanda dos consumidores (BALESTRIN; VARGAS, 2004). Neste sentido, socializamos por meio deste artigo a experiência da disciplina Comportamento Empreendedor oferecidas em 15 cursos da Universidade de Uberaba que propõe uma atividade prática em que 0 aluno é estimulado a elaborar um Plano Estratégico Pessoal. Nesta atividade os alunos desenvolvem as onze etapas de um PEP compreendendo uma importante ferramenta que o auxiliará no planejamento, organização, acompanhamento e avaliação de seus objetivos e ações.
\end{abstract}

Palavras-chave: Metodologias ativas. Empreendedorismo. Atividade prática. 


\section{A UNIUBE formando mais que profissionais}

A dinâmica da sociedade contemporânea tem acelerado o processo de busca por conhecimento, e, de forma mais acentuada, tem promovido e ampliado a necessidade de alternativas para a melhoria organizacional. Neste sentido, a formação profissional tornou-se uma exigência para a pessoa que quer manter-se sintonizada com a dinâmica atual que abriga grande diversidade de formas de trabalho e, por conseguinte, técnicas de comunicação, de disseminação e de construção de conhecimentos. Ao mesmo tempo, tal sociedade exige a arte de administrar tempo, recursos, produção e alternativas para a melhoria da qualidade de vida das populações. A Universidade de Uberaba tem como missão promover o ensino e a geração do conhecimento, formando o profissional compromissado com uma sociedade justa. Nessa perspectiva busca formar cidadãos nas diferentes áreas do conhecimento, inserindo-os em setores profissionais, e aptos para participarem do desenvolvimento da sociedade brasileira. Ciente dos desafios que a atual realidade do mercado de trabalho apresenta, especialmente no tocante às competências empreendedoras, tem buscado explicitar na elaboração dos seus Projetos Pedagógicos, o compromisso educativo com 0 fortalecimento da criatividade e do comportamento empreendedor.

\section{O Empreendedorismo e as características do Comportamento Empreendedor}

Existem inúmeras definições de empreendedorismo que estão em sua maioria baseadas em duas correntes: os economistas que o ligam à inovação e os comportamentalistas que associam com criatividade e atitudes. Os principais economistas que trataram do tema são Cantillon, Jean-Baptiste Say e Schumpeter que foi um dos pioneiros a tentar reunir as duas correntes em um conceito mais abrangente de empreendedor que relacionasse inovação e criatividade.

Para Dolabela (2008) ser empreendedor não é somente acumular conhecimentos, mas possuir atitudes, comportamentos, formas de percepção do mundo e de si mesmo, é voltar-se para atividades em que haja risco e capacidade de inovar, perseverança e convivência com a incerteza. Este autor afirma que é o empreendedor, em qualquer área, aquele que sonha com o objetivo de transformar sonho em realidade. Schumpeter (1982), vai mais além no conceito afirmando ser empreendedor quem transforma uma ideia em uma inovação de sucesso. Segundo ele "qualquer que seja o tipo, alguém só é um empreendedor quando efetivamente levar a cabo novas combinações, e perde esse caráter assim que tiver montado o seu negócio, quando dedicar-se a dirigi-lo, como outras pessoas dirigem seus negócios" (SCHUMPETER, 1982, p. 56). O grupo comportamentalistas define que pessoas empreendedoras têm certos traços de 
personalidade e aspectos cognitivos comuns. Autores desta corrente se dedicam a estudar e tentar definir quais são estas características. $\mathrm{O}$ espírito empreendedor é um potencial de qualquer ser humano e necessita de algumas condições indispensáveis para se materializar e produzir efeitos. Entre essas condições estão, no ambiente macro, a democracia, a cooperação e a estrutura de poder tendendo para a formação de rede. (DOLABELA, 2008, p. 24)

Como pode ser visto, muitos fatores contribuem para o desenvolvimento das habilidades empreendedoras, dentre eles destacam a cultura, a religião, aspectos inatos de personalidade, e também as experiências adquiridas por meio de capacitações e treinamentos com foco em conscientização e desenvolvimento de características empreendedoras, bem como apontar as possibilidades de carreira para empreendedores. Neste sentido, a aprendizagem empreendedora foi definida por Cope (2005) como "um processo dinâmico de conscientização, reflexão, associação e aplicação que envolve transformar a experiência e o conhecimento em resultados aprendidos e funcionais. Compreende conhecimento, comportamento e aprendizagem afetivo-emocional."

Indo mais além, a pedido da ONU (Organização das Nações Unidas) a empresa americana de consultoria McBeer, de McClelland e Burham, fez um profundo estudo a partir do qual definiu algumas importantes características do comportamento empreendedor. Este estudo teve como intuito a verificação de quais eram as características mais presentes nas pessoas que obtinham sucesso, para que de forma basilar as suas conclusões norteassem o desenvolvimento e a criação de cursos capazes de despertar nos indivíduos a principais características dos empreendedores já consagrados. O resultado do referido estudo foi a compilação das dez Características do Comportamento Empreendedor destacadas a seguir.

A primeira característica é a busca de oportunidades e iniciativa. Trata-se necessidade de desenvolver a capacidade de antecipar aos fatos e de criar oportunidades de negócios com novos produtos e serviços. É importante compreender que um empreendedor com essas características bem trabalhadas além de agir com proatividade, antecipando- se às situações, busca a possibilidade de expandir seus negócios e aproveita oportunidades incomuns para progredir. A segunda característica apresentada é a persistência. Nesta característica é apontada a importância de se trabalhar o alcance do sucesso através do enfrentamento de desafios e de se enxergar os obstáculos como fonte de energia. $\mathrm{O}$ empreendedor com esta característica bem desenvolvida reavalia, insiste ou muda seus planos para superar objetivos e esforça-se além da média para atingi-los. Outra característica identificada pela consultoria que a 
ONU solicitou é a de correr riscos calculados, que envolve a disposição em de enfrentar situações em que não se tem grandes certeza dos resultados, mas há grande crença na potencialidade. Destacamos que empreendedores não correm qualquer tipo de risco e não se aventuram sem antes avaliar as alternativas para tomar decisões. Eles, em verdade, compreendem uma tentativa de reduzir as chances de erro mediante riscos calculados, moderados e que tenham boas chances de sucesso. A próxima característica é a exigência de qualidade e eficiência que está relacionada com a disposição para sempre buscar fazer mais e de uma maneira melhor. O empreendedor com esta característica busca incessantemente a melhoria contínua nos negócios e projetos que atua e valoriza a satisfação do cliente, procurando constantemente exceder suas expectativas por meio do cumprimento de prazos e altos estabelecimento de padrões de qualidade. O comprometimento é outra característica observada em pessoas empreendedoras. Apontamos que esta característica envolve sacrifício pessoal, colaboração com os funcionários e esmero com os clientes. As pessoas que possuem esta habilidade desenvolvida assumem a responsabilidade sobre seu sucesso ou fracasso, bem como atuam em conjunto com sua equipe para atingir os resultados valorizando o relacionamento do cliente a longo prazo. Os Empreendedores não tomam conhecimento se uma tarefa é fácil ou difícil, se é preciso fazer, se comprometem e realizam, é isso que frequentemente os leva ao sucesso. A sexta característica compreende a busca de informações. Envolve a atualização constante de dados e informações sobre clientes, fornecedores, concorrentes e sobre o próprio negócio. É relevante compreender que o empreendedor com esta característica desenvolvida se envolve pessoalmente na busca e análise de informações e quando necessário recorre à opinião de especialistas para tomar decisões. Inclusive, por essa ter essa aptidão, o empreendedor assumi riscos calculados, uma vez que está sempre munido de informações. A sétima característica trabalhada é o estabelecimento de metas. Destacamos que consiste em compreender a importância de estabelecer objetivos que sejam claros, específicos e que contemplem o curto, médio e longo prazo, além de serem desafiadores, embora possíveis. Estabelecer metas é fundamental para empreendedores que tem visão a longo prazo, pois possibilitam que se defina o que queremos e a partir daí, que criemos indicadores que nos permitam verificar se estamos alcançando o que foi planejado. O empreendedor só estabelece objetivos inteligentes, no formato SMART[1] - específico, mensurável, alcançável, relevante e temporal. Outra característica refere-se ao planejamento e monitoramento sistemáticos. Pessoas empreendedoras possuem a necessidade de desenvolverem a definição de prazos para a realização de tarefas, bem como a organização delas de maneira objetiva, a fim de que possam medir e avaliar os resultados. É fundamental que se perceba que quem desenvolve esta característica age por etapas para enfrentar grandes desafios, adequa rapidamente seus planos às mudanças e variáveis de mercado e avalia indicadores no 
processo de tomada de decisão. A nona característica é persuasão e rede de contatos. Esta característica envolve o uso de estratégia para influenciar e persuadir os outros, além de destacar a importância de se relacionar com pessoas chave que possam ajudar no alcance de seus objetivos. É essencial entender que empreendedores que têm este atributo bem desenvolvido criam estratégias para conseguir apoio de pessoas e organizações para realização e ampliação de seus projetos, mantém redes de contato e constroem bons relacionamentos comerciais e sociais. A última característica apresentada é independência e autoconfiança. Refere-se à necessidade de desenvolver a autonomia para agir e manter sempre a confiança no sucesso. Realçamos que a pessoa com essa característica confia em sua própria opinião e em sua capacidade de enfrentar desafios sendo otimistas e determinadas mesmo que diante de oposição. Mas, é importante ressaltar que a autoconfiança e independência próprias da personalidade do empreendedor vem das outras das outras características as quais ele também possui.

\section{A disciplina Comportamento Empreendedor e o PEP - Plano estratégico pessoal}

Tendo como base as características discorridas anteriormente, a disciplina Comportamento Empreendedor está prevista institucionalmente nas organizações curriculares dos seguintes cursos da modalidade a distância Universidade de Uberaba: Administração, Ciências Contábeis, Engenharia Civil, Engenharia Elétrica, Física, Pedagogia, Matemática, Letras, Tecnologia em Agronegócio, Gestão de Cooperativas, Gestão de Recursos Humanos, Gestão Financeira, Gestão Pública, Marketing e Processos Gerenciais. Seu objetivo principal é possibilitar que o aluno desenvolva uma capacidade empreendedora, dando ênfase ao perfil do empreendedor, apresentando técnicas de identificação e aproveitamento de oportunidades, aquisição e gerenciamento de recursos necessários ao negócio, estimulando a criatividade e a aprendizagem proativa. Neste sentido, o conteúdo programático é organizado de modo a preparar os alunos para a identificação de oportunidades de novos empreendimentos, apresentar e possibilitar o desenvolvimento das características empreendedoras; fornecer conhecimentos e ferramentas auxiliares à gestão desses empreendimentos; orientar o desenvolvimento de competências em gestão de negócios, bem como desenvolver o senso crítico, a percepção e identificação de estratégias inovadoras, para a aplicação dos conhecimentos no campo econômico, político e/ou social. Para que isso seja possível, nesta disciplina tratamos de vários assuntos pertinentes ao empreendedorismo mesclando teoria e prática por meio da atividade que será apresentada a seguir.

Planejar a vida não significa adotar uma postura radical e inflexível como muitos pensam, como se nada pudesse ser alterado ou modificado. O planejamento torna 0 
objetivo e o processo mais claros, mais compreensíveis e a partir daí, é possível vislumbrar com mais exatidão o caminho a seguir. Sem planejamento, as ações são aleatórias e dispersas. Com planejamento, elas se tornam focadas e certeiras. A sorte pode até levar um ou outro a conquistar o sucesso profissional, financeiro ou pessoal. Mas depender da sorte é arriscado pois na inércia da vida, podemos acabar muito bem sucedidos ou insatisfeitos com o que conquistamos. Realizações exigem iniciativa. Iniciativa exige determinação. E determinação sem planejamento resulta em desperdício de esforços e de tempo. Pensando nisso, por compreender que o planejamento pessoal é a chave para a autorrealização e para o sucesso pessoal, incluindo a motivação e o equilíbrio entre a vida pessoal e profissional, propomos aos alunos a refletir mais sobre sua vida em todos os aspectos. Levamo-nos a pensar onde se encontram atualmente, aonde gostariam de chegar e como fazer para alcançar os seus objetivos e metas.

Nesta atividade os alunos desenvolvem as onze etapas de um PEP (Planejamento Estratégico Pessoal) compreendendo uma importante ferramenta que o auxiliará no planejamento, organização, acompanhamento e avaliação de seus objetivos e ações. Incentivamos os alunos a serem realistas, otimistas e utilizarem esta oportunidade para fazer uma grande reflexão sobre sua vida, seus objetivos e os caminhos que deve seguir para conquistá-los. A primeira etapa compreende na denominação do Planejamento Estratégico Pessoal, ou seja, o momento em que o aluno desenvolve um nome para seu PEP. Deixamos claro que esta escolha deva, de fato, representar a identidade daquele que o faz. No decorrer dos anos muitos nomes criativos surgiram, inclusive, sendo possível identificar traços reveladores dos perfis dos alunos já nesta etapa. Em seguida, deve ser definida a data do PEP, ou seja, o prazo de vigência do planejamento do aluno com início e fim. A data de início será o momento no qual ele começou a pensar sobre seu planejamento e a final será definida sendo solicitado que crie um planejamento a longo prazo. Este prazo é fundamental para que o aluno possa acompanhar seu sucesso no alcance do que foi planejado. O terceiro passo consiste na descrição do perfil, no qual o aluno irá se apresentar e contar sua história. Nesta etapa, pedimos que faça uma verdadeira reflexão e comece contando sobre quem é, onde nasceu, sua família, sua vida hoje, enfim tudo que possa lhe descrever. Sugerimos que imagine estar escrevendo uma carta se apresentando para alguém que não o conhece. Esse passo é importantíssimo para que o aluno desenvolva seu autoconhecimento. É muito gratificante ler os perfis descritos pelos alunos, pois verificamos que eles realmente se dedicam e fazem uma viagem do passado ao presente, no intuito de se definirem e descreverem detalhadamente quem são e contarem suas histórias.

Ainda com o intuito de aprofundar seu autoconhecimento, a próxima etapa consiste na análise SWOT (FOFA), na qual define suas forças e fraquezas e as oportunidades e 
ameaças que enxergam para o alcance de seus objetivos. Esta etapa é importante para que o aluno consiga identificar claramente quais são as habilidades e competências que têm melhor desenvolvidas, seu diferencial e perceba suas fraquezas que são características que precisa melhorar. Na parte externa ele deve analisar o ambiente geral e apontar quais são as oportunidades, ou seja, eventos que podem facilitar e contribuir para o alcance de seus objetivos e as ameaças que são variáveis que podem dificultar o atingimento de suas metas. Esta etapa possibilita ao aluno se conhecer melhor e se preparar para enfrentar os desafios futuros, pois passa a conhecer seus pontos fortes, aqueles que precisa desenvolver, as oportunidades existentes e as ameaças que precisa neutralizar. O próximo passo é a definição de sua missão que é a forma como querem contribuir para a sociedade e a razão de sua existência. Esta etapa é importante para que comecem a pensar e construir uma missão que seja desafiadora e empolgante, que lhe dê sentido, seja transformadora e relevante para a sociedade e que seja prazeroso ao buscar realizar.

Após a definição da missão, o aluno deve criar a sua visão que é o que quer ser no futuro e como quer ser reconhecido pessoal e profissionalmente. Em seguida é solicitado ao aluno que defina seus valores que são os princípios, atitudes e comportamentos que defende. A definição dos conceitos estratégicos missão, visão e valores facilita ao aluno após descrever sua razão de existir, seus objetivos e crenças, a pensar qual as ações que deverá desenvolver para alcançar suas metas. O oitavo passo é o momento no qual o aluno deve pensar e definir seus objetivos. Solicitamos que sejam pelo menos três e pensados no curto, médio e longo prazo sobre sua vida pessoal e carreira. Lembramos que os objetivos devem ser específicos, mensuráveis, atingíveis, relevantes e tenham prazo (SMART). Esta etapa é importante, pois é nela que os alunos param para pensar a partir de seus sonhos e desejos quais são seus reais objetivos e iniciam o planejamento formal. Todos planejam, mas é um grande erro mantermos somente em pensamento aquilo que queremos. A partir do momento que escrevemos nossos objetivos estabelecemos um contrato com nós mesmos e temos um rumo definido. Por fim, devemos sempre reavaliar o que foi planejado com o intuito de verificarmos se estamos no caminho certo para atingirmos ou se devemos alterar alguma parte de nosso planejamento.

A próxima etapa se constitui na definição das estratégias que serão utilizadas para alcançar os objetivos. Tão importante quanto a definição dos objetivos é pensar em quais são os possíveis caminhos para se alcançar o que é desejado e definir qual serão as ações a serem tomadas e seguidas para se obter o sucesso esperado. Ter um plano de ação pensado e formalizado é uma vantagem competitiva importante no cenário atual no qual as mudanças ocorrem rapidamente, pois nos tornamos conscientes e 
preparados para enfrentar possíveis desafios que possam surgir. No décimo passo, os alunos devem apontar as parcerias, que são as pessoas ou empresas que serão fundamentais para sua trajetória e alcance de suas metas. Nossa rede de relacionamentos é um patrimônio do qual devemos cuidar e manter sempre e ter a estratégia de aumentar nosso círculo de conhecidos com pessoas que possam contribuir para que nos tornemos pessoas melhores e mais capazes de realizar nossos sonhos. Por último, com base nas CCEs (Características do Comportamento Empreendedor) estudadas, pedimos que os alunos definam quais são as três menos desenvolvidas e criem uma meta para cada uma no sentido de desenvolvê-las. Esta etapa é fundamental, pois após conhecer as Características do Comportamento Empreendedor é preciso se avaliar em relação a cada uma delas e colocá-las em prática. Portanto, esta etapa permiti que o aluno novamente se reavalie em relação às CCEs e crie um plano de ação para desenvolver aquelas habilidades que julga necessárias. Percebemos que antes do PEP vários alunos não haviam parado realmente para se avaliar em relação a essas características e pensar como desenvolvê-las.

\section{Resultados obtidos}

A universidade que se propõe a ser empreendedora desenvolve um programa de formação de empreendedores, que visa preparar o aluno para o mercado de trabalho, passando a ser o empreendedorismo uma segunda competência somada à área profissional, diferente das demais instituições que têm apenas a disciplina na grade de seus cursos voltados para a área. Segundo Rabbior (1990) os objetivos da educação empreendedora são:

\footnotetext{
Conscientizar a respeito do empreendedorismo e da carreira empreendedora, lançando sementes para o futuro. Influenciar/desenvolver atitudes, habilidades e comportamentos empreendedores. Desenvolver qualidades pessoais relacionadas às competências necessárias para o mundo moderno: criatividade, assumir risco e assumir responsabilidade. Incentivar e desenvolver empreendedores. Estimular a criação de negócios/novas iniciativas. Apoiar o desenvolvimento destas. Gerar empregos. Desenvolver conhecimentos, técnicas e habilidades focados no mundo dos negócios e necessários para a criação de uma empresa.
}

Entende-se que o ensino do empreendedorismo envolve o desenvolvimento de conhecimento, habilidades, atitudes e qualidades que visam a aplicação da teoria em situações reais permitindo ao aluno ser capaz de realizar transformações no ambiente em que vive e liderar projetos. Para tanto, várias metodologias como aprendizagem pela ação, aprendizagem contextual, aprendizagem baseada em problemas e aprendizagem cooperativa são utilizadas no sentido de colocar o aluno como o centro e autor de sua aprendizagem, nas quais é valorizado o processo que permiti com que várias competências sejam desenvolvidas. 
$\mathrm{Na}$ Universidade de Uberaba as atividades são mediatizadas e acompanhadas por professores-tutores on-line. A interação e a interdisciplinaridade são, também, garantidas na forma de elaboração do material didático impresso e digital: livros de apoio, elaborados pela equipe docente dos cursos da UNIUBE, guias e manuais com tratamento didático pedagógico adequado para a modalidade a distância e das ferramentas disponíveis no ambiente virtual de aprendizagem - AVA.

A Sala de Aula Virtual, também denominada de Área da disciplina curricular, corresponde ao ambiente específico da disciplina e é composto por ferramentas que possibilitam organizar, desenvolver e dar suporte ao processo de aprendizagem EAD, tais como: Orientações Gerais, Painel de Atividades, Tira-dúvidas, Biblioteca Virtual da Pearson e Orientações de estudo semanais. Por meio destas orientações são utilizados os seguintes recursos para a construção do aprendizado: textos, links, hiperlinks, videoaulas, leituras obrigatórias e complementares e atividades de avaliação continuada (abertas e fechadas). O material didático compreende: os livros de apoio dos componentes curriculares estudados pelo aluno durante o curso, as vídeo aulas gravadas pelos professores responsáveis, as leituras complementares disponibilizadas no ambiente virtual bem como as web aulas agendadas para interação. O aluno, no desenvolvimento das suas atividades, conta com as orientações de estudos, indicando o passo-a-passo a ser seguido com vistas a concretização da aprendizagem. Nesse processo, no desenvolvimento das suas atividades de avaliação continuada a distância, em caso de dúvidas de conteúdo, terá o auxílio do seu professor-tutor on-line na ferramenta "Tira-dúvidas".

Várias das características estudadas teoricamente no curso são trabalhadas por meio da atividade proposta como planejamento, cumprimento de prazos, busca de informações na realização do trabalho, importância da rede de contato dentre outras. A fim de demonstrar os resultados obtidos até o momento com a atividade descrita neste artigo, optamos por dar voz aos principais sujeitos do processo de ensino-aprendizagem. Finalizamos com alguns depoimentos de alunos que vivenciaram o PEP e, consequentemente, desenvolveram características do comportamento empreendedor.

\footnotetext{
"A experiência que vivenciei sobre escrever o PEP, foi gratificante. Com toda essa correria do dia-a-dia ás vezes esquecemos de quem somos. Esquecemos dos nossos medos e dos anseios, deixando os projetos para depois. Escrevendo o PEP, fiz um resgate das minhas qualidades há um tanto esquecida. É importantíssimo, pois é um incentivo para inovação e melhorias no processo de organização da vida pessoal . Traçar uma estratégia e definir os rumos ou caminhos a seguir, fica mais fácil de realizar um projeto".JANAINA DOMINGOS DE ASSIS - Aluna do curso de Pedagogia do Polo de Guanhães - MG
}

Fazer o PEP, foi muito importante para planejar minha vida pessoal, pois através dele consegui me planejar e definir estratégias para alcançar meus objetivos. Sei, que não é tão fácil porém sei que com dedicação , persistência , planejamento e controle vou conseguir alcançar meu objetivo. CARLA CRISTINA FONSECA REIS 
REZENDE - Aluna do curso de Administração do Polo de Barbacena - MG

“O PEP é uma ferramenta administrativa fundamental para empresas, além disso, é um instrumento que pode, quando empregado também na vida pessoal. Como pessoa, nunca me havia deparado com tal oportunidade de aplicação no maior empreendimento que pode existir, nossa vida. A estruturação do PEP proporcionou 0 autoconhecimento, a sintonização em relação ao passado, presente e futuro na linha cronológica da vida e a (re)programação dos objetivos almejados. Para aquela pessoa que se encontra um pouco perdida em relação aos sonhos e suas perspectivas, o PEP servirá como mapa e bússola para verificar o meio e direcionar os esforços rumo ao objetivo desejado. Foi assim comigo." RONALD SILVA - Aluno do curso de Ciências Contábeis do Polo de Araxá - MG

A partir da aplicação da atividade prática sobre comportamento empreendedor, e dos relatos de experiência feitos pelos alunos em nossos meios de comunicação/interação, temos bastante segurança em afirmar que as expectativas dos estudantes que clamam pela aplicabilidade da teoria/prática tem sido atendidas. Assim, podemos afirmar que, mesmo estando na fase embrionário do desenvolvimento e uso de metodologias ativas, elas se configuram em verdadeiros projetos de aprendizado e permitem ao discente extrapolar o que lhe é proposto no PPC do seu curso.

\section{REFERÊNCIAS}

BALESTRIN, A.; VARGAS, L. A complementaridade de conhecimentos nos processos de inovação. In: XVIII ENANPAD - Encontro Nacional dos Programas de PósGraduação em Administração, Anais. 2004, Curitiba. XVIII ENANPAD, 2004 COPE, Jason. Toward a Dynamic Learning Perspective of Entrepreneurship, 2005. Disponivel em: < http://journals.sagepub.com/doi/abs/10.1111/j.1540-6520.2005.00090.x $>$. Acesso em 07/05/18.

DOLABELA, F. Oficina do empreendedor. Rio de Janeiro: Sextante, 2008.

RABBIOR, Y. Elements of a successful entrepreneurship / economic / education program. In: Kent, C. (Eds.) Entrepreneurship Education - Current developments, Future direction, N.Y. Quorum Books, p.53-65, 1990.

SCHUMPETER, Joseph Alois. Teoria do desenvolvimento econo?mico: uma investigac?a?o sobre lucros, capital, cre?dito, juro e o ciclo econo?mico. Sa?o Paulo: Abril Cultural, 1982

1- Criada por Peter Drucker é considerada uma poderosa técnica utilizada para validar qualquer objetivo e auxiliar no planejamento de maneira eficiente. É um acrônimo, palavra formada pelas iniciais, de um termo em inglês: Specific, Measurable, Achievable, Realistic e Time-based. 